\title{
UMA EXPERIÊNCIA DE RESGATE DA MEMÓRIA da sAÚde meNTAL do paraná
}

\author{
An experience of memory rescue of mental health in \\ the state of Paraná
}

Silvia Beatriz Ussyk Manzarra' ${ }^{1}$ Rejane Cristina Teixeira Tabuti² ${ }^{2}$ Tiago Pereira Nocera ${ }^{3}$, Denise de Castro ${ }^{4}$, Osvaldo Tchaikovski Júnior ${ }^{5}$

\footnotetext{
1. Hospital Colônia Adauto Botelho. Secretaria de Estado da Saúde do Paraná. ORCID: https://orcid. org/0000-0002-4278-3213

2. Secretaria de Estado da Saúde do Paraná. ORCID: https://orcid.org/0000-0002-0003-1793

3. Escola de Saúde Pública do Paraná. Secretaria de Estado da Saúde do Paraná. ORCID: https://orcid. org/0000-0002-2971-3464

4. Secretaria de Estado da Saúde do Paraná. ORCID: https://orcid.org/0000-0002-8981-0370

5. Hospital Colônia Adauto Botelho. Secretaria de Estado da Saúde do Paraná. ORCID: https://orcid. org/0000-0002-3910-9471
}

CONTAтO: Rejane Cristina Teixeira Tabuti | Endereço: Rua Piquiri, 170 | Rebouças. | Curitiba- PR | E-mail: rejaneteixeira@sesa.pr.gov.br/rejane.teixeira@yahoo.com.br

COMO CITAR: Manzarra SBU, Tabuti RCT, Nocera TP, Castro D, Tchaikovski Junior O. Uma experiência de resgate da memória da saúde mental do Paraná. R. Saúde Públ. 2018 Dez;1(2):141-151

(c) COPYRIGHT Esta obra é disponibilizada nos termos da Licença Creative Commons - 4. 0

RESUMO O objetivo deste trabalho é contextualizar sobre a importância da preservação da memória institucional da saúde mental e a implantação do espaço memorial em um hospital psiquiátrico que compõe a Rede de Unidades Hospitalares Próprias da Secretaria de Estado da Saúde do Paraná. Parte-se do pressuposto que além de viabilizar o acesso a objetos e documentos do hospital, o espaço do memorial contribui de forma significativa para a reflexão sobre a evolução dessa instituição, que é o único hospital público especializado em psiquiatria, do Paraná. Assim, entende-se que preservar a memória institucional não é só resgatar o passado. É, sobretudo, contribuir para a percepção das diferenças e reconhecimento dos limites de cada período.

RESUMO Hospital Psiquiátrico. Documento Histórico. Memória Institucional. Saúde Mental 
ABSTRACT The objective of this work is to contextualize the importance of preserving the institutional memory of mental health, and the implantation of the memorial space in a psychiatric hospital that makes up the Network of Hospital Units of the State Department of Health of Paraná. It is assumed that, besides providing access to objects and documents of the hospital, the memorial contributes significantly to the reflection on the evolution of this institution, which is the only public hospital specialized in psychiatry in Paraná. Thus, it is understood that preserving the institutional memory is not only to rescue the past. It is, above all, to contribute to the perception of differences, and recognition of the limits of each period.

KEYWORDS: Psychiatric Hospital. Historical Document. Institutional Memory. Mental Health

\section{INTRODUÇÃO}

D

reservar a memória e o patrimônio institucional é estratégia administrativa e política que garante a construção da identidade, demonstra o compromisso das organizações com suas ações e atividades, permite a realização de futuras pesquisas e, ao permitir o relato da trajetória das lutas, contradições, retrocessos e avanços que construíram estes espaços coletivos em que os processos sociais se desenvolvem, dá subsídios para a defesa das conquistas, especialmente no campo da saúde pública, em um momento em que o Sistema Único de Saúde (SUS)" sofre ataques e propostas de desmanche por amplas camadas de classes hegemônicas nos campos políticos, econômicos e sociais.

Observa-se que, especialmente em um país em que a cultura da preservação do patrimônio ainda é incipiente como o Brasil, a preservação da memória ainda não é vista como estratégica para as organizações. Com a complexidade crescente das relações e processos de trabalho e flexibilidade dos novos modelos de administração, conhecer a cultura da empresa, expressa nos registros de processos administrativos, operacionais e técnicos, permite o desenvolvimento e a continuidade das atividades organizacionais?.

Aponta-se também que preservar a memória em organizações, favorece a apropriação por parte dos funcionários das experiências compartilhadas coletivamente, o que gera aprofundamento do vínculo e do sentimento de pertencimento com as atividades, demonstrando o compromisso da empresa com sua área de atuação².

A história da saúde pública no Brasil demonstra que as ações estão presentes desde os tempos da colônia, império e do início da nova república, observando-se o caráter excludente e pouco abrangente nesses períodos. Só ao final do século $X X$, com as ações e lutas que culminaram com a construção do SUS, um papel mais significativo neste campo passa a ser embarcado como política de Estado.

No contexto do Estado do Paraná, os registros de ações de saúde se dão a partir da emancipação de São Paulo, em 1853. Em 1947, o antigo Departamento Estadual de Saúde, vinculado 
à Secretaria d'Estado dos Negócios do Interior, Justiça e Instrucção Publica, passou à categoria de Secretaria de Estado 5 .

Identifica-se que a preservação da memória institucional na Secretaria de Estado de Saúde do Paraná (SESA-PR) é ainda tímida e pouco desenvolvida, encontrando-se ainda poucas iniciativas fragmentadas para seu resgate, o que não permite a construção de fontes confiáveis para pesquisa e uma narrativa consistente desta trajetória. Como exemplo destas iniciativas, podem ser registradas: a criação da casa da memória da Saúde Pública na década de 1980, sob coordenação do Dr. Lindolfo Fernandes, a qual publicou diversas obras, algumas das unidades da pasta-8; a organização do acervo documental sob guarda do Arquivo Público do Paraná, elaboração de projeto "Guia de Acervos do Paraná", em 1999, por grupo de trabalho constituído pela seção paranaense da Associação Natural de História (ANPUH); e a constituição da Rede Paranaense de Preservação da Memória da Saúde Pública (Rede Memória Saúde Pública) ${ }^{9}$, entre outros.

Em meados da década de 90 um grupo de profissionais do Hospital Colônia Adauto Botelho (HCAB)", preocupados com a preservação da memória, iniciaram a coleta de documentos escritos, instrumentais, fotos e demais objetos, que foram organizados numa casa defronte ao hospital, como um Museu que contava a história da assistência à saúde mental do HCAB. Existiam também muitos projetos visando à qualificação da assistência, bem como a reinserção social dos usuários.

A partir do ano de 2014, foi iniciado processo de organização, gestão e abertura ao público do "Espaço Memorial Hospital Colônia Adauto Botelho (HCAB)", o qual reúne objetos e documentos de diversos tipos que registram a memória desta organização. Localizado no município de Pinhais-PR, o referido hospital possui 64 anos de história ${ }^{10}$ no desenvolvimento de ações de cuidado aos pacientes com transtornos mentais e necessidades decorrentes de álcool e outras drogas, sendo importante repositório da história do desenvolvimento da saúde mental no Paraná.

Tito Moreira Salles, que começou a trabalhar no Hospital Colônia Adauto Botelho em 1954 quando cursava o segundo ano de medicina, relata em seu manuscrito que o mesmo possui "histórias fantásticas"11 e, por meio de seus registros, é possível verificar suas lutas, desafios, tristezas e conquistas. É possível visualizar nesta trajetória, as políticas de saúde, concepções, conceitos e visões de mundo que permearam a própria saúde mental no Brasil, desde as políticas de assistência psiquiátrica, iniciadas a partir da década de 40 , até os movimentos pela reforma destes serviços de saúde e a luta antimanicomial, em tempos mais recentes ${ }^{10}$

Observando-se a fragmentação dos registros e objetos, correndo o risco de se deteriorarem e serem perdidos na instituição, a direção geral do HACB sensibilizou-se para disponibilizar infraestrutura física e pessoal para o tratamento deste acervo, bem como sua exposição à população geral interessada desta história corporificada materialmente nestes documentos. Este relato de experiência objetiva descreve a trajetória da construção deste espaço, fundamentada nos conceitos da memória institucional e preservação do patrimônio, bem como dos conhecimentos trazidos pela Ciência da Informação e História, considerando o contexto da importância do HCAB para a memória da saúde mental do Paraná.

A Coordenação Estadual de Saúde Mental, preocupada em registrar os fatos que retratam o desenvolvimento da história da política de saúde mental no Estado, reuniu vários documentos e ouviu pessoas que contribuíram ao longo do tempo. Reconhecendo a valorosa contribuição de técnicos e coordenadores, organizou um encontro, onde foram relembrados momentos relevantes que culminaram no primeiro ambulatório implantado no estado, em 1944, anterior à inauguração do HCAB. Também houve a implantação de ambulatórios em municípios do interior, bem como o apoio presencial 
aos municípios, regada a muitas viagens e trabalho que buscava a qualidade da assistência em saúde mental.

Espera-se que esta narrativa estimule a preservação da memória nas diversas unidades da SESA-PR, conscientizando colaboradores e direção de que cada uma delas pode e deve estruturar ações do mesmo cunho, dentro de suas possibilidades. Considerando a importância social das atividades realizadas pelos serviços de saúde, é essencial que a instituição responsável por estas ações em âmbito estadual estruture e garanta acesso a estas fontes, possibilitando a criação compartilhada de conhecimento e estimulando futuras pesquisas.

A partir de 2017, a direção-geral da SESA constituiu grupo de trabalho formado por profissionais de diversas áreas, tanto da própria secretaria quanto integrantes do DEAP (Departamento de Arquivo Público do Paraná) para a realização da iniciativa "Rede Paranaense de Preservação da Memória da Saúde Pública (Rede Memória Saúde Pública)", a qual tem como objetivo, entre outras estratégias, "contribuir para a preservação da memória da Saúde Pública no Paraná", através do estímulo ao desenvolvimento destes espaços de memória nas unidades da instituição ${ }^{12}$. Devido ao trabalho já realizado, o HCAB foi convidado para compor o grupo.

\section{FUNDAMENTAÇÃO TEÓRICA}

A memória traz ao presente a materialização dos fatos do passado, em uma construção seletiva que traz o contexto familiar, social e nacional coletivamente construído. Para os gregos antigos, a memória era uma deusa, denominada Mnemosine, que lembrava a recordação dos grandes feitos heroicos e era mãe de todas as chamadas artes liberais. Esta concepção nos remete ao fato de que a história é a cientificidade da memória, em um processo de seleção de fatos $^{13}$, e dentro desta mesma seleção se revelam as concepções de mundo propostas no desenrolar da história.
A memória institucional constitui-se do conjunto de registros materiais e imateriais que compõem sua história. Os registros materiais compõem-se dos documentos, entendidos esses de sua forma mais ampla possivel como a "unidade de registro de informações, qualquer que seja o suporte ou formato"14, sendo estas todas as materializações das ações organizacionais, sejam elas textuais, audiovisuais, fonográficas, objetos etc.

A reunião destes registros revela um ato consciente, que envolve uma vontade administrativa, política e econômica para a preservação da memória institucional. Entre os benefícios que esta ação traz às organizações estão: iluminação do passado para criação de projetos de futuro; preservação do patrimônio; resgate das tradições e possibilidade de análise crítica destas; envolvimento dos colaboradores com a trajetória das atividades, gerando sentimento de pertencimento, entre outros 2,15 .

No Brasil, a preservação do patrimônio registrado é estipulada pela Constituição Federal de 1988, quando esta afirma, em seu art. 23, que é competência comum da União, dos Estados e do Distrito Federal: "III- proteger os documentos, as obras e outros bens de valor histórico, artístico e cultural, os monumentos, as paisagens notáveis e os sítios arqueológicos ${ }^{16 " . ~ A ~ C o n s t i t u i c ̧ a ̃ o ~}$ brasileira também elenca os bens que constituem o patrimônio cultural brasileiro, entre os bens de natureza material e imaterial, no art. 216, sendo estes:

I- as formas de expressão;

II- os modos de criar, fazer e viver;

III- as criações científicas, artísticas e tecnológicas;

IV- as obras, os objetos, documentos, edificações e demais espaços destinados às manifestações artístico-culturais;

V- os conjuntos urbanos e sítios de valor histórico, paisagístico, artístico e arqueológico, paleontológico, ecológico e científico. 
Também concretizam o dever do Estado com a preservação dos fatos que marcam sua história, tais como o Decreto-Lei n 25 , de 30 de novembro de 2017, que organiza a proteção do patrimônio histórico e artístico e nacional, definindo o que constitui o patrimônio e as formas de tombamento ${ }^{17}$ e o Decreto $n^{\circ}$ 3.551, de 4 de agosto de 2000 , que institui o registro de bens culturais de natureza imaterial que constituem o patrimônio brasileiro ${ }^{18}$, entre outros marcos legislativos.

Para a história, registros que compõem a memória institucional só poderão servir como fonte caso preservem sua organicidade, entendida esta como o princípio arquivístico que mantém a relação natural entre os documentos e as atividades realizadas por uma instituição ${ }^{14}$, e que estas fontes primárias estejam acessíveis aos interessados, podendo servir para pesquisa historiográfica ${ }^{19}$.

A preservação e o resgate dos documentos para a construção da história são possíveis através da interlocução entre as áreas da Ciência da Informação e da História.

Na Ciência da Informação, relacionam-se a memória e a informação, considerada esta última como a informação registrada que fornece as peças as quais permitirão construção e reconstrução da memória e da formação da identidade, considerando que esta só será alcançada com a organização, preservação e divulgação destes registros. Assim,

Essas operações incluem o aspecto seletivo, que envolvem o binômio lembrar e esquecer, onde a decisão sobre o que constituirá a memória é compreendida como uma disputa, ou uma negociação, entre grupos sociais, permeadas por questões políticas e ideológicas, por vezes antagônicas. A preservação dessa memória é associada, também, a espaços físicos socialmente instituídos e legitimados para sua custódia, tais como arquivos, bibliotecas e centros de documentação ${ }^{20}$.

Permeando a Ciência da Informação, a área da arquivologia é o eixo principal que subsidia este processo de seleção e constituição da memória, ao lidar propriamente com os chamados documentos arquivísticos, que são aqueles que são gerados através das atividades das organizações, registrando seus feitos através do tempo. Este conjunto de documentos acumulados e tecnicamente processados constitui elemento dinamizador da pesquisa histórica.

Nesse sentido, arquivologia e história devem atuar harmonicamente, pois a primeira busca a materialização do conhecimento em que a segunda deverá atuar na produção de sentidos, através de interpretações, identificação de movimentos, desvelando ou ocultando discursos, ou seja, produzindo aquilo que se chama conhecimento propriamente historiográfico²1.

Nessa relação entre documentos arquivísticos e a seletividade da memória, os conceitos da área da gestão de documentos propõem os princípios que possibilitarão a uma organização definir aqueles documentos que servirão como registro de sua trajetória e possuirá valor além daquele pelo qual este foi originalmente gerado, o que implica que este pode ser utilizado como fonte para pesquisa.

A gestão de documentos trata do processamento técnico que permite o controle do ciclo de vida do documento dentro de sua organização, referindo-se à produção, tramitação, uso, avaliação e arquivamento destes em sua fase corrente e intermediária, visando sua eliminação ou recolhimento. O recolhimento é a operação que rege a entrada de documentos em sua fase permanente, na qual estes documentos possuem valor de memória e qualificados como fontes de pesquisa.

A partir do preconizado por Schellenberg ${ }^{22}$. a gestão de documentos permite a avaliação dos documentos para a definição de seu ciclo vital, considerando para sua classificação sua função dentro de uma organização. Assim, os documentos que possuem valor primário, ou seja, o uso pelo qual eles são originalmente produzidos (administrativo, legal, jurídico, fiscal, contábil, financeiro), se movimenta nas fases correntes e intermediárias do arquivo, de acordo com sua frequência e tipos de uso; encerrado seu valor primário, os documentos devem possuir valor secundário (valor de pesquisa 
histórica e cultural) para serem de guarda permanente; do contrário, podem ser eliminados.

Esta ação de valoração do documento em primário e secundário, bem como sua classificação de acordo com a função que exerce, favorece um olhar administrativo apurado para intervenção no uso de documentos, evitando seu acúmulo desnecessário e desordenado, sistematizando estrategicamente aqueles que devem ser preservados por seu valor histórico ${ }^{23}$

Através desta fundamentação, demonstrase que a preservação e o resgate da memória institucional de uma organização implicam em uma atuação intencional da administração desta na construção de sua história, o que se verifica na conjugação dos procedimentos técnicos de seleção, organização e disseminação trazidos pela Ciência da Informação e no conhecimento analítico que instrumentalizará estas informações, trazidas pela História e áreas correlatas.

Nas seções a seguir estarão relatadas as ações que permitiram ao HCAB reunir e divulgar os materiais que estão sob sua guarda, favorecendo a construção da memória dos serviços de saúde mental no Estado do Paraná.

\section{ANÁLISE CONTEXTUAL}

Para muitos, a imagem de hospitais psiquiátricos inaugurados nos anos 50, como é o caso do HCAB, ainda está ligada à dor, sofrimento, desumanidade, muito distante de uma instituição hospitalar com a finalidade de prestar assistência à pessoa em sofrimento mental.

No caso específico do HCAB, o passado registra, de fato, uma instituição superlotada, com prestação de cuidados limitada e questionável, porém a história, e somente ela, vai esclarecer alguns pontos como bem pontuado por Casagrande e Wadi (2011) destacando a fala do Dr.Jayme Etzel, diretor interino do HCAB:
Face à evidente disparidade entre as entradas e saídas de doentes, está o hospital com sua lotação triplicada, ou seja, no momento atual, 906 internados, dos quais apenas a metade está em camas, está com sua indumentária mais ou menos adequada, recebe alimentação no horário normal no refeitório. Convém mencionar que a outra metade não está desamparada; recebe sua alimentação em horário especial e está acomodada nos pavilhões, sem cama é bem verdade, também está vestida, isto tudo, porém longe, muito longe mesmo do que deveria ocorrer. Em virtude deste estado de coisas, a cozinha, a lavanderia, funcionam 12 a 14 horas diárias, os servidores de um modo geral não têm tido os seus horários de folga e em consequência é patente o descontentamento ${ }^{10}$.

Pensando neste contexto, e considerando a importância do HCAB para a história da saúde mental no Paraná, direção e colaboradores, observando o estado de deterioração, fragmentação e desorganização dos documentos e objetos acumulados pelo Hospital ao longo do tempo, decidiram disponibilizar espaço físico para a reunião destes materiais. Também considerando a importância social da referida instituição, este mesmo espaço foi organizado de forma a permitir acesso livre à população interessada, na perspectiva que estas ações deem visibilidade ao desenvolvimento das ações de saúde mental no Paraná e possibilitem a realização de estudos e pesquisas.

\section{DESCRIÇÃO DA EXPERIÊNCIA}

A ideia do HCAB ter um Espaço do Memorial já vinha sendo alimentada há um bom tempo, para reunir os objetos e documentos levantados em ocasiões anteriores e os documentos que estavam em caixas arquivo, sob a responsabilidade da Comissão de Documentos do hospital.

Com a identificação do local reservado ao Espaço do Memorial, no primeiro semestre de 2014. 
veio o trabalho de melhorias, basicamente pintura, para bem receber a história do HCAB.

Assim, em 10 de outubro de 2014, o espaço da antiga unidade ${ }^{7}$ feminina, depois enfermaria clínica, formado por uma ampla sala de aproximadamente $64 \mathrm{~m}^{2}$, passou a ser identificada como Espaço do Memorial. O resultado da organização do espaço pode ser observado na figura 1.

Figura 1 Espaço do memorial do HCAB

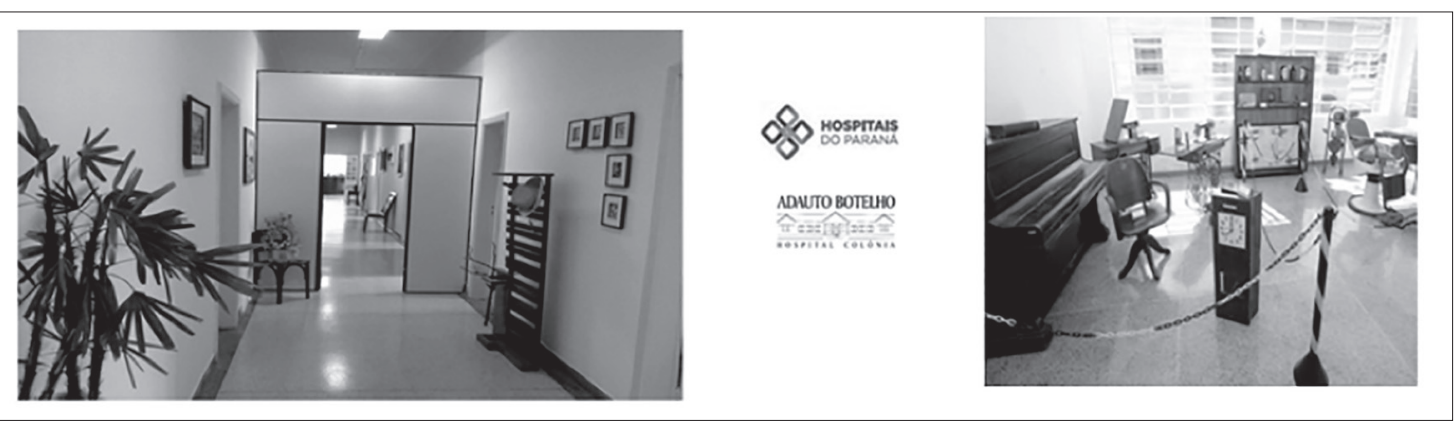

Fonte: Acervo HCAB

Nesta altura, a biblioteca técnica do hospital ocupava uma sala em outro andar. Lá se poderiam encontrar diversos livros sendo que boa parte deles foi doada por médicos que trabalharam no hospital, além de relatórios e fotos da época da inauguração do hospital, de eventos festivos como festas Juninas e de Natal, passeios entre outras atividades. Neste espaço estava também uma verdadeira "joia": cópia de um trabalho escrito e datilografado pelo Dr. Tito Moreira Salles, citado no início deste relato, com a seguinte dedicatória:
"Aos colegas e amigos que continuam nessa obra, dedico este trabalho, radiantes que a continuidade do nome Adauto está assegurada - 23/06/1980".

Os documentos com valor histórico que estavam sob a guarda da Comissão de Documentos do hospital foram encaminhados para o Espaço do Memorial, selecionados e registrados. Segundo levantamento da Rede de Preservação da Memória da Saúde Pública do Paraná24, entre os documentos e objetos disponíveis no espaço estão:

Tabela 1. Documentos e objetos com valor de memória localizados no HCAB

\begin{tabular}{l|c|c|c|c|c}
\hline \multicolumn{1}{c|}{ Título: } & Tipo: & $\begin{array}{c}\text { Tipo: } \\
\text { [Outros] }\end{array}$ & $\begin{array}{c}\text { Ano/Número/ } \\
\text { Página: }\end{array}$ & Conservação: & Observações: \\
$\begin{array}{l}45 \text { Caixas Arquivos com } \\
\text { documentos }\end{array}$ & $\begin{array}{c}\text { Livros, Folhas } \\
\text { soltas, fotos, } \\
\text { peças }\end{array}$ & Diversos & Boa & $\begin{array}{c}\text { Material previamente } \\
\text { selecionado e } \\
\text { arquivado em caixas } \\
\text { arquivo identificadas } \\
\text { por título e ano }\end{array}$ \\
$\begin{array}{l}\text { Movimento de 1954 - Hospital } \\
\text { Colônia Adauto Botelho }\end{array}$ & Folha Solta & Folha Solta & 1954 & Boa & Relatório Qualitativo \\
$\begin{array}{l}\text { Movimento do Primeiro } \\
\text { Trimestre de 1955 }\end{array}$ & Folha Solta & Boa & Relatório Qualitativo \\
$\begin{array}{l}\text { Movimento 1956 Hospital } \\
\text { Colônia Adauto Botelho }\end{array}$ & & 1956 & Boa & Relatório Qualitativo \\
\hline
\end{tabular}




\begin{tabular}{|c|c|c|c|c|c|}
\hline Título: & Tipo: & $\begin{array}{c}\text { Tipo: } \\
\text { [Outros] }\end{array}$ & $\begin{array}{l}\text { Ano/Número/ } \\
\text { Página: }\end{array}$ & Conservação: & Observações: \\
\hline $\begin{array}{l}\text { Relatório anual dez. } 1957 \\
\text { Hospital Colônia Adauto } \\
\text { Botelho }\end{array}$ & Folha Solta & & 1957 & Boa & $\begin{array}{l}\text { Relatório } \\
\text { Qualitativo com } \\
\text { fotos }\end{array}$ \\
\hline $\begin{array}{l}\text { Movimento } 1955 \text { Hospital } \\
\text { Colônia Adauto Botelho }\end{array}$ & Folha Solta & & 1955 & Boa & $\begin{array}{l}\text { Relatório } \\
\text { Qualitativo }\end{array}$ \\
\hline $\begin{array}{l}\text { Relatórios dos meses de } \\
\text { Julho a Dezembro de } 1955\end{array}$ & Folha Solta & & 1955 / Julho & Boa & $\begin{array}{l}\text { Relatórios } \\
\text { Qualitativos }\end{array}$ \\
\hline $\begin{array}{l}\text { Relatórios dos meses de } \\
\text { Janeiro a Dez. de } 1956\end{array}$ & Folha Solta & & $\begin{array}{c}1956 \text { / janeiro } \\
\text { a dezembro }\end{array}$ & Boa & $\begin{array}{l}\text { Relatórios } \\
\text { Qualitativos }\end{array}$ \\
\hline $\begin{array}{l}\text { Relatórios dos meses de } \\
\text { Janeiro a Dez. de } 1957\end{array}$ & Folha Solta & & $\begin{array}{c}1957 \text { /janeiro } \\
\text { a dezembro }\end{array}$ & Boa & $\begin{array}{l}\text { Relatórios } \\
\text { Qualitativos }\end{array}$ \\
\hline $\begin{array}{l}\text { Relatórios Janeiro a Abril } \\
\text { de } 1958\end{array}$ & Folha Solta & & $\begin{array}{c}1958 \text { / janeiro } \\
\text { a abril }\end{array}$ & Boa & $\begin{array}{l}\text { Relatórios } \\
\text { Qualitativos }\end{array}$ \\
\hline $\begin{array}{l}\text { Ata Lançamento Pedra } \\
\text { Fundamental do Hospital } \\
\text { Colônia para Psicopatas em } \\
\text { terreno anexo à Granja do } \\
\text { Canguiri }\end{array}$ & $\begin{array}{l}\text { Quadro com moldura } \\
\text { de madeira e vidro }\end{array}$ & $\begin{array}{l}0,69 \times \\
0,54 \mathrm{~cm}\end{array}$ & Boa & & \\
\hline Planta prédio do hospital & $\begin{array}{l}\text { Quadro com moldura } \\
\text { de madeira e vidro }\end{array}$ & $1,10 m \times 0,76$ & Boa & & \\
\hline $\begin{array}{l}\text { Quadro } 1^{\text {a }} \text { Neurocirurgia no } \\
\text { Hospital - Lobotomia Pré- } \\
\text { Frontal. Cirurgião Dr. José } \\
\text { Portugal Pinto }\end{array}$ & $\begin{array}{l}\text { Quadro com moldura } \\
\text { de madeira e vidro } \\
\text { contendo } 05 \text { fotos }\end{array}$ & $0,36 \times 0,54$ & Boa & & \\
\hline $\begin{array}{l}\text { Estatuto dos Funcionários } \\
\text { Públicos Civis do Estado Lei } \\
\text { n } 293 \text { de } 24 \text { Nov. de } 1949 . \\
\text { Imp. Of. Est.1952 }\end{array}$ & Manual & $\begin{array}{l}0,2 \mathrm{~cm} \mathrm{X} \\
0,16 \mathrm{~cm}\end{array}$ & Boa & & \\
\hline $\begin{array}{l}\text { Regulamento do } \\
\text { Departamento de Saúde / } \\
\text { Secr. de Saúde Pública; Imp. } \\
\text { Oficial Estado } 1955\end{array}$ & Manual & $0,16 \times 0,23$ & Boa & & \\
\hline $\begin{array}{l}\text { Aparelho de Eletrochoque, } \\
\text { marca JAFAR, mod. 0-8 - } \\
\text { 0-201 }\end{array}$ & $\begin{array}{l}\text { Caixa com botões de } \\
\text { Volt. e de Tempo e } \\
\text { entrada para eletrodos }\end{array}$ & $\begin{array}{c}0,24 \times 0,25 \times \\
0,9 \text { com ( sem } \\
\text { tampa) }\end{array}$ & Boa & & \\
\hline $\begin{array}{l}\text { Quadro "Inaugurado em } \\
\text { 05/06/1954; fotografia } \\
\text { naquela oportunidade" }\end{array}$ & $\begin{array}{l}\text { Quadro com moldura } \\
\text { de madeira e foto }\end{array}$ & $\begin{array}{c}0,20 \mathrm{~cm} \mathrm{X} \\
0,27 \mathrm{~cm}\end{array}$ & Ruim & & \\
\hline $\begin{array}{l}\text { Quadro com foto aérea do } \\
\text { hospital }\end{array}$ & $\begin{array}{l}\text { Quadro com foto, } \\
\text { moldura de madeira } \\
\text { e vidro }\end{array}$ & $\begin{array}{l}0,25 \mathrm{~cm} \mathrm{X} \\
0,31 \mathrm{~cm}\end{array}$ & Boa & & \\
\hline $\begin{array}{l}\text { Lençol de contenção para } \\
\text { pacientes }\end{array}$ & $\begin{array}{l}\text { Lona com fitas de } \\
\text { couro e fivelas }\end{array}$ & $1,05 \mathrm{~m} \times 1,55 \mathrm{~m}$ & Boa & & \\
\hline Camisa de Contenção & Tecido: algodão & $\begin{array}{c}0,64 \mathrm{~cm} \mathrm{X} \\
0,75 \mathrm{~cm}\end{array}$ & Boa & Boa & \\
\hline
\end{tabular}

Fonte: Rede de Preservação da Memória da Saúde Pública do Paraná 
Assim, reconhecendo a importância da preservação do patrimônio documental e de objetos com valor histórico, o Espaço do Memorial do HCAB foi inaugurado em 2014, no dia Mundial da Saúde Mental. Ocupando uma área onde havia sido instalada uma enfermaria clínica, o Espaço do Memorial do HCAB está aberto para toda a comunidade hospitalar (funcionários, pacientes e seus familiares) e para interessados, sejam pesquisadores ou participantes de visita técnica.

\section{RESULTADOS E DISCUSSÃO}

Merlo e Konrad (2015) ${ }^{19}$ esclarecem que a memória é representada por meio de registros de informação, qualquer que seja o suporte em que está contida e que seja passível de recuperação (acesso). Assim, por meio do Espaço do Memorial do HCAB se tem acesso a tantas informações sobre o hospital e demais acontecimentos da época ligados à assistência às pessoas com sofrimento mental, como, por exemplo, o registro do Dr. Tito Moreira Salles (1980) sobre a superlotação:

O espírito dominante desde a direção até o atendente era no sentido de lutar contra o estigma de 'depósito' de psicóticos.

A propósito da superlotação existe estudo estatístico do Dr. Herley Mehl - Diretor do Hospital de 1963 a 1965, acredito eu - no qual ele afirma que são internados relativamente mais doentes naturais de outros Estados do que naturais do Paraná (Revista Médica do Paraná vol. 27, $n^{\circ}$ 1958).

Este contingente não necessitava somente de cuidados psiquiátricos, necessitava e muito de cuidados gerais de saúde. Havia casos em que a patologia mental era apenas reflexo de sofrimento orgânico. Vem aí a necessidade da instalação de outros serviços ${ }^{11}$.

Fatos pitorescos também são relatados pelo autor supracitado como:

Não havia nada que lembrasse o que é hoje terapia ocupacional, no entanto, de modo empírico conseguimos abastecer a cozinha de verduras, carne de porco, frango e ovos. (...) Ainda nesta faina de ocupar o elemento humano que havia em excesso, e no afã de distraí-los com o trabalho, mil vezes melhor do que ficar sentado num banco do pátio vendo o dia passar, planejamos construir estradas. A estrada para o Rio Iraí foi feita assim, o objetivo era de levar para lá nossos pacientes a fim de eles pescarem"1.

Cita-se a seguir um último relato, ilustrando como a organização destes registros permite o resgate de memórias, histórias e o desenvolvimento das ações em saúde mental:

\begin{abstract}
Um tcheco, que fora prisioneiro dos alemães na II Guerra, e como tal, trabalhara em ajustamentos de aparelhos de precisão de aviões de guerra, foi durante muito tempo nosso hóspede; fora internado em extremo depauperamento como só o álcool sabe produzir.

Já em recuperação pediu e obteve licença para ficar trabalhando em nossa oficina. Tínhamos balanças antropométricas tão antigas que nem mesmo a fábrica, através de sua representada queria mais consertar. Alegava-se falta de peça para aquele modelo obsoleto. Ludwig (nome fictício) fabricou peças, fundiu-as, ajustou e deixou as balanças perfeitas. Foram muito usadas para pesar fumo (tabaco) cortado para distribuir em cotas pelos pavilhões segundo o peso e de acordo com o número de internos em cada unidade ${ }^{11}$
\end{abstract}

Ressalta-se que pela iniciativa do Espaço do Memorial, o HCAB foi reconhecido pela Direção Geral da SESA com um certificado de honra ao mérito, por ocasião da já referida abertura da Rede Paranaense de Preservação da Saúde Pública (Figura 2).

Nesse sentido, a perspectiva é de continuidade da reunião de registros que comprovem a memória do Hospital, com a manutenção do Espaço Memorial do HCAB e sua disponibilidade para acesso. 
Figura 2. Certificado de Honra ao Mérito pela organização do Espaço Memória do HCAB

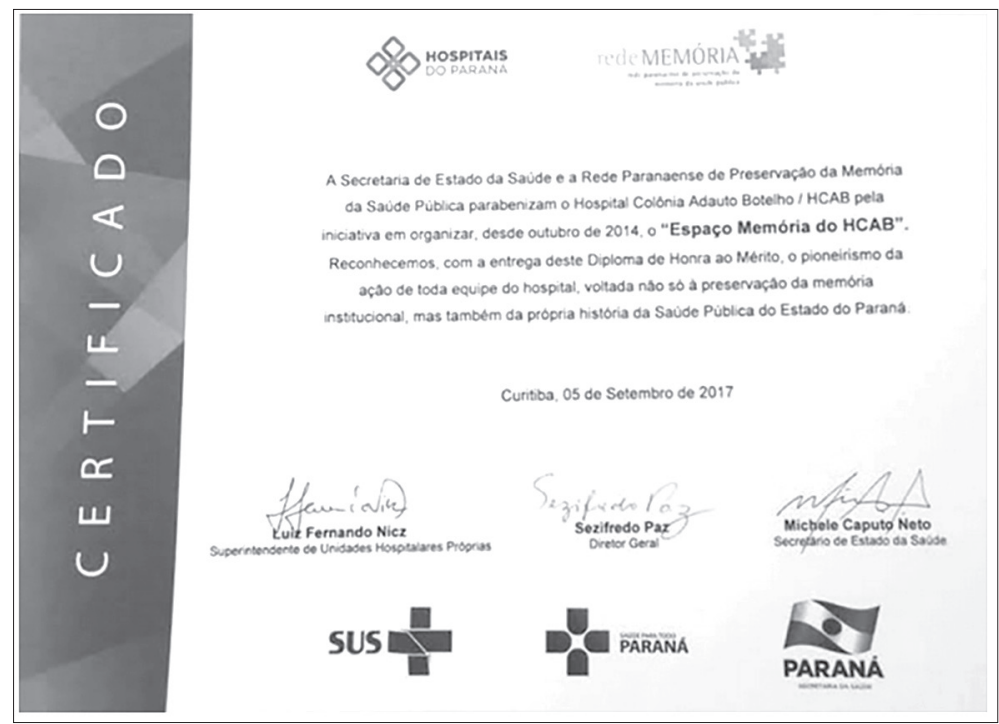

\section{CONSIDERAÇÕES FINAIS}

Na perspectiva da iniciativa da SESA da Rede Paranaense de Preservação da Memória da Saúde Pública, este relato de experiência procurou estimular a reflexão e despertar os colaboradores das diversas unidades para a criação de espaços de memória próprios, a exemplo do aqui relatado. Este mesmo espaço, de acordo com as necessidades e possibilidades de cada órgão, pode ser desde uma sala, uma mesa, um espaço em um armário ou apenas uma gaveta, desde que haja organização destes registros e a possibilidade de acesso aos mesmos, institucionalizando a preservação da memória em cada local.

Na perspectiva da história da saúde mental no Paraná, espera-se que este relato também seja um primeiro passo para a reunião de registros que até agora estão fragmentados e dispersos em todos os locais em que ações neste âmbito foram realizadas.

O resgate histórico da saúde mental do Estado do Paraná está em processo de construção. A iniciativa e a existência do Memorial instituem um local privilegiado para continuar recebendo registros de fatos, fotos e objetos que construíram a trajetória da saúde mental.

Os achados até o momento indicam ações relevantes em vários municípios do interior que muito contribuíram nos caminhos da assistência à saúde mental no Estado e que poderão trazer novos elementos para esses registros.

Entendemos que os benefícios desta ação poderão oportunizar a realização de consultas, pesquisas com vistas à reflexão do passado visando à criação de projetos futuros, bem como a preservação da memória da saúde mental no Estado.

\section{REFERÊNCIAS}

1 Goulart S. Patrimônio documental e história institucional. São Paulo: Associação de Arquivistas de São Paulo; 2002.

2 Centro de Memória: manual básico para implantação. São Paulo: Itaú Cultura, 2013.

3 Rosen G. Uma história da saúde pública. São Paulo: HUCITEC; 1994. 
4 Bertolli Filho C. História da saúde pública no Brasil. São Paulo: Ática; 2001

5 Fernandes Jr. LR. A Secretaria de Estado da Saúde do Paraná: suas origens e sua evolução no periodo de 1853-1983. Curitiba: Fundação Caetano Munhoz da Rocha; 1987.

6 Fernandes Jr. LR. O Centro de Saúde de Londrina. Curitiba: Secretaria de Estado da Saúde do Paraná; 1992.

7 Fernandes Jr. LR. A Escola de Saúde Pública do Paraná sem aspas. Curitiba: Secretaria de Estado da Saúde do Paraná; 1995.

8 Juk BV. Fernandes Jr. LR. A tísica (através dos tempos) no Paraná. Curitiba: Casa de Memória da Saúde Pública do Paraná: 1992.

9 Secretaria de Estado da Saúde, Secretaria de Estado da Administração e Previdência, Secretaria de Estado da Cultura. Rede Paranaense de Preservação da Memória da Saúde Pública (Rede Memória Saúde Pública). Espaç. saúde. 2017 Jul;18(1):219-21.

10 Bonna Casagrande A de, Wadi YM. Os primeiros anos do Hospital Colônia Adauto Botelho: em busca de uma instituição modelar. In: Anais do XXVI Simpósio Nacional de História - ANPUH [evento na internet], 2011 jul. 17-22, São Paulo, Brasil. São Paulo: ANPUH-SP. 2011. p. 1-18. [acesso em 28 ago 2018]. Disponível em: http://www.snh2011.anpuh.org/resources/anais/14/1300305291_ ARQUIVO_ST58-ArtigoYonissa-Attiliana.pdf.

11 Salles, TM. História do HCAB. 1980. Disponibilidade: Espaço Memorial do Hospital Colônia Adauto Botelho.

12 Projeto organiza memória da saúde pública no Paraná [Internet] CONASS. 2017 ago 6. [citado 2018 Ago 25]Disponível em: http:// www.conass.org.br/projeto-organiza-memoria-da-saude-publicano-parana/.

13 Le Goff J. História e memória. 5. ed. Campinas: Ed. da UNICAMP 2003

14 Arquivo Nacional. Dicionário brasileiro de terminologia arquivística. Rio de Janeiro: Arquivo Nacional; 2005.

15 Jardim JM. A invenção da memória nos arquivos públicos. Ci. Inf 1995;25 (2).

16 Brasil. Constituição (1988). Constituição da República Federativa do Brasil.

Brasília, DF: Senado Federal; 1988.

17 Brasil. Decreto-Lei n 25, de 30 de novembro de 1937. Organiza a proteção do patrimônio histórico e artístico nacional. Diário Oficial da União. 6 dez 1937.

18- Brasil. Decreto $n^{\circ}$ 3.551, de 4 de agosto de 2000. Institui o Registro de Bens Culturais de Natureza Imaterial que constituem patrimônio cultural brasileiro, cria o Programa Nacional do Patrimônio Imaterial e dá outras providências. Diário Oficial da União. 7 ago 2000.

19 Merlo F, Konrad GVR. Documento, história e memória: a importância da preservação do patrimônio documental para acesso à informação. Inf. Inf. 2015 abr;20(1):1-26.

20 Oliveira EB de. O conceito de memória na Ciência da Informação no Brasil: uma análise da produção científica dos programas de pós-graduação. [tese]. Brasília: Universidade de Brasília; 2010

21 Barros DS, Neves DAB. Arquivo e memória: uma relação indissociável. Trans. 2009 Abr:21(1):55-61.

22 Schellenberg TR. Arquivos modernos: princípios e técnicas. 2. ed. Rio de Janeiro: FGV: 2002.
23 Medeiros NL de, Amaral CMG do. A representação do ciclo vital dos documentos: uma discussão sob a ótica da gestão de documentos. Em Ques. 2010 dez;16(2):297-310.

24 Paraná. Secretaria de Estado da Saúde. Rede de Preservação da Memória da Saúde Pública do Paraná. Relatório do levantamento de documentos e objetos de valor histórico existentes nas unidades da SESA. 2017. 44p. Disponibilidade: Biblioteca da ESPP/ SESA. 